\title{
The empathy gap: building bridges to the good life and the good society (/review/10.5860/CHOICE.46-5910)
}

Trout, J. D. (/search?exactauthor=Trout, J. D) Viking, 2009

306p, $9780670020447 \$ 25.95$

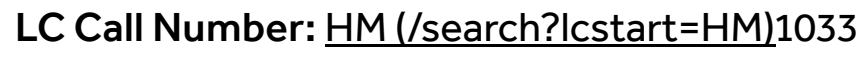

This is a wide-ranging book about the frailties of human decision making and the toll "normal" irrationality has taken on the well-being of individuals and of society as a whole. The title is a little misleading, since Trout (philosophy, Loyola Univ.) offers more a survey of cognitive psychology principles and their applications than a treatment of "empathy" in particular. But the book is intelligent, well written, and well researched, and it covers topics ranging from the personal to the political. It is reminiscent of several recent books applying cognitive psychology to social and political problems, perhaps most notably Cass Sunstein's Why Societies Need Dissent (CH, Apr'04, 41-4946). Trout provides a number of intelligent suggestions based on principles from cognitive psychology for strategies that will improve both the lives of individuals and the greater society.

Summing Up: Recommended. Upper-division undergraduates through faculty and professionals; general readers.

Reviewer: R. Levine (/search?reviewer=R. Levine), California State University--Fresno

Recommendation: Recommended

Readership Level: General Readers, Upper-division Undergraduates, Graduate Students, Researchers/Faculty, Professionals/Practitioners

Interdisciplinary Subjects:

Subject: Social \& Behavioral Sciences - Psychology (/search?q=\&sbj[]=psy)

Choice Issue: jun 2009 vol. 46 no. 10

Choice Review \#: 46-5910

Review DOI: 10.5860/CHOICE.46-5910 